\title{
De tuchtrechtspraak Nivra 1978-1983
}

\section{Inleiding}

Dit artikel sluit aan bij eerdere overzichten van de tuchtrechtspraak NIVRA over de jaren 1968-1973 (MAB november 1973, 47e jaargang, no. 10, blz. 476494) en 1973-1978 (MAB februari 1979, 53e jaargang, no. 2, blz. 46-58). Hieronder een overzicht van de in de afgelopen 5 jaar behandelde tuchtzaken:

\begin{tabular}{|c|c|c|c|c|c|c|c|}
\hline $\begin{array}{l}\text { Verslag } \\
\text { periode }\end{array}$ & $\begin{array}{l}\text { Aan- } \\
\text { hangig }\end{array}$ & $\begin{array}{l}\text { Nieuwe } \\
\text { klachten }\end{array}$ & $\begin{array}{l}\text { Bestuur } \\
\text { NIVRA }\end{array}$ & $\begin{array}{l}\text { Inge- } \\
\text { trokken }\end{array}$ & $\begin{array}{l}\text { Onge- } \\
\text { grond }\end{array}$ & $\begin{array}{l}\text { Ge- } \\
\text { grond }\end{array}$ & $\begin{array}{l}\text { Totaal } \\
\text { afgedaan }\end{array}$ \\
\hline $1978 / 79$ & 14 & 10 & 1 & 1 & 2 & $\begin{array}{l}5^{\circ} \\
5^{*} \\
1^{* * *}\end{array}$ & 14 \\
\hline $1979 / 80$ & 11 & 13 & 2 & 1 & 2 & $\begin{array}{l}3^{*} \\
1 *\end{array}$ & 7 \\
\hline $1980 / 81$ & 19 & 11 & - & 6 & 6 & $\begin{array}{l}2^{\circ} \\
3^{*} \\
3^{* *}\end{array}$ & 20 \\
\hline $1981 / 82$ & 10 & 14 & - & 3 & 4 & $\begin{array}{l}3^{*} \\
1^{* *}\end{array}$ & 11 \\
\hline $1982 / 83$ & 13 & 19 & - & 2 & 5 & $\begin{array}{l}2^{*} \\
1^{* *} \\
1^{* * *} \\
\end{array}$ & 11 \\
\hline
\end{tabular}

\footnotetext{
- geen maatregel

* waarschuwing

* * berisping
}

Uitspraken in beroep:

1978/79: 1 (beroep verworpen)

1979/80: 6 (beroep verworpen)

1980/81: 1 (beroep verworpen)

2 (zwaarder oordeel)

1981/82: 5 (beroep verworpen)

2 (lichter oordeel)

1 (zwaarder oordeel)

1982/83: 5 (beroep verworpen)

De voortdurende stijging van het aantal zaken blijkt als we de afgelopen drie tijdvakken van vijf jaar met elkaar vergelijken: in 1968-1973 werden 36 zaken, in 1973-1978 57 zaken en in 1978-1983 70 zaken aangebracht. Uitspraken van de Raad van Tucht (RvT) en van de Raad van Beroep (RvB) 
werden tot 1980 in De Accountant gepubliceerd. Sedert dat jaar wordt de Jurisprudentie Tuchtrechtspraak afzonderlijk uitgegeven. Ik zal daarom hieronder voor vindplaatsen verwijzen, hetzij naar De Accountant (De Acc.), hetzij naar de door het NIVRA gepubliceerde Jurisprudentie Tuchtrechtspraak (JT).

Hieronder bespreek ik een aantal van de in de afgelopen periode gepubliceerde uitspraken van de tuchtcolleges NIVRA. In totaal zijn 49 zaken gepubliceerd in de periode september 1978 tot september 1983. Ter vergelijking: in de periode 1973-1978 werden 27 zaken gepubliceerd (zie MAB 1979, blz. 51) en in de periode 1968-1973 slechts 12 zaken (zie MAB 1973, blz. 488, noot 21). Veel uitspraken zijn nogal casuïstisch en bieden weinig aanknopingspunten voor algemene conclusies. Ik beperk mij daarom tot die uitspraken waaruit normen voor de beroepsuitoefening van registeraccountants zijn af te leiden.

In paragraaf 2 worden uitspraken besproken waarin bezwaren werden onderzocht die betrekking hadden op het optreden van registeraccountants anders dan in de controlefunctie. In paragraaf 3 wordt aandacht besteed aan gevallen waarin de betrokken registeraccountant de getrouwheid van een verantwoording had onderzocht.

\section{De registeraccountant niet optredend in de accountantsfunctio}

Uit de uitspraken van de NIVRA-tuchtcolleges in procedures waarin geklaagd werd over werkzaamheden die registeraccountants verrichten anders dan de controle van een verantwoording blijkt dat het kan gaan om zeer uiteenlopende activiteiten. Ik noem: het fungeren als tolk (RvT 1978-7; De Acc. september 1979, blz. 53), het bepalen van de waarde van een aandelenpakket (RvT 1979-1; De Acc. januari 1979, blz. 378 en JT 1982-2), het aangaan van een huurovereenkomst met een cliënt (RvT 1979-5; De Acc. september 1979, blz. 46) en het rapporteren omtrent de draagkracht van één der partijen in een echtscheidingsprocedure (JT 1981-6).

In een, relatief groot, aantal gevallen gaat het om het verlenen van administratieve hulp in de vorm van het verzorgen van een belastingaangifte (RvT 1979-4; De Acc. juni 1979, blz. 704; JT 1981-8 en JT 1983-4) of het opstellen van een jaarrekening (JT 1981-2, JT 1981-4, JT 1982-12 en JT 1983-6). De registeraccountant begeeft zich hier op wat Groeneveld in zijn noot onder JT 1981-2 het 'natuurlijk terrein' van de accountant-administratieconsulent noemt. Hij oppert in zijn noot onder JT 1983-6 bezwaren tegen een situatie waarin de registeraccountant zich zowel belast met het opstellen van jaarstukken als het controleren daarvan. Het behoort niet tot de taak van de controlerende registeraccountant de administraties van de gecontroleerden zelf te voeren. Hij zou een goedkeurende verklaring afgeven over zijn eigen werk. Zoiets is alleen in zeer bijzondere gevallen toelaatbaar en dan nog aldus Groeneveld - 'onder degelijke controle en onder verantwoording van een ander maatschapslid'.

De tuchtrechter heeft echter weinig moeite met zo'n situatie; in ieder geval is een dergelijke situatie nimmer veroordeeld. De GBR gaat er zelfs vanuit 
dat een registeraccountant die een verantwoording afgeeft, deze ook zelf controleert; ook als het een (mede) door hem zelf afgelegde verantwoording betreft (artikel $6 \mathrm{GBR}$ ). Dit geldt, tenzij een andere functie wordt vermeld dan die van accountant of de woorden 'niet gecontroleerd', dan wel 'geen accountantscontrole toegepast', worden vermeld. De accountant die dit had nagelaten werd berispt (JT 1981-4). De accountant die een kritische beschouwing aan de door hem opgestelde jaarrekening had gewijd, had volgens de RvT niet duidelijk gemaakt wat de werkelijke aard van zijn werkzaamheden was geweest, maar een verwijt wordt hem hiervan niet gemaakt omdat de betrokkene duidelijk had aangegeven dat hij geen accountantscontrole had toegepast (JT 1981-2).

Een geval dat in accountancy-kringen nogal de aandacht heeft getrokken, betrof een registeraccountant die als directeur van een $\mathrm{BV}$, met als werkterrein het verzorgen van administraties, voor deze BV reclame had gemaakt. $\mathrm{Hij}$ had daarbij tevens gewezen op de mogelijkheid de controlewerkzaamheden te laten verrichten door de maatschap waaraan hij als openbaar accountant was verbonden. Volgens de uitspraak van de RvT van 7 juni 1981 had hij daarmee schade toegebracht aan de eer van de stand der registeraccountants. De Raad beschouwt dit als oneerlijke concurrentie ten opzichte van de andere registeraccountants en de accountant-administratieconsulenten voor wie een reclameverbod geldt. De betrokken registeraccountant had daarom gehandeld in strijd met artikel 5 en artikel 28 GBR. De Raad maakt hem hiervan echter geen verwijt en legt geen maatregel op omdat betrokkene in onzekerheid kon verkeren over de draagwijdte van het reclameverbod (JT 1982-9). Men mag aannemen, dat de onzekerheid, althans op dit punt, door deze uitspraak, die intussen door de RvB is bekrachtigd, is opgeheven.

Deze door het bestuur van het NIVRA aangespannen tuchtprocedure had nog een interessant vervolg omdat ook het gedrag van de voorzitter van de raad van bestuur van de accountantsmaatschap waar de betrokkene lid van was tuchtrechtelijk werd onderzocht. Dit eveneens op verzoek van het NIVRA-bestuur. Het gaat hier om de vraag in hoeverre vennoten van een accountantsmaatschap tuchtrechtelijk verantwoordelijk zijn voor het optreden van één hunner. Het staat wel vast dat als een vennoot handelt ter uitvoering van en overeenkomstig het in de maatschap vastgestelde beleid, de andere vennoten tuchtrechtelijk medeverantwoordelijk zijn indien hij daarbij in strijd handelt met de GBR (JT 1982-11). Maar hoe nu als de maatschap op het betreffende punt (nog) geen beleid had vastgesteld? Maakt het, zo kan men zich afvragen, in dit verband nog verschil of de registeraccountant onder eigen naam optreedt dan wel onder de naam van de maatschap?

Artikel 24 leden 2 en $3 \mathrm{GBR}$ eisen dat, als een registeraccountant onder gemeenschappelijke naam optreedt met anderen, maatregelen worden getroffen voor het kunnen dragen van de medeverantwoordelijkheid die daaruit voortvloeit. In de onderhavige procedure besliste de RvT dat dit artikel alleen van toepassing kan zijn op de medeverantwoordelijkheid voor gedragingen van een lid van de maatschap die als openbaar accountant en onder 
de naam van de maatschap optreedt. Derhalve niet voor diens optreden als directeur van een BV. Uit het feit dat de voorzitter van het college van bestuur van de maatschap tegen het maken van reclame pas maatregelen had genomen toen het NIVRA-bestuur hiertegen bezwaar had gemaakt, leidt de RvT af dat betrokkene hiertegen niet aanstonds bezwaar had gemaakt en aldus heeft gedoogd dat ten behoeve van de maatschap reclame werd gemaakt. Daarmee had hij artikel 28 GBR overtreden (RvT 7 juni 1981, JT 1982-10).

In hoger beroep echter werd betrokkene ook op dit laatste punt vrijgesproken omdat vast kwam te staan dat hij de betreffende registeraccountant heeft laten wijzen op de gedrags- en beroepsregels die hij bij de publiciteit in acht moest nemen en op redelijke korte termijn gepaste maatregelen heeft genomen toen hij van die publiciteit achteraf kennis had genomen (RvB 14 april 1982, JT 1982-10).

Een omstandigheid die nogal eens aanleiding vormt voor tuchtklachten (zie ook MAB 1979, blz. 53), is dat brieven afkomstig van registeraccountants soms in juridische procedures aan de rechter worden overgelegd. Als dergelijke brieven niet aan de eis van objectiviteit en duidelijkheid (artikel 6 GBR) voldoen kunnen ze de afzender een tuchtrechtelijke maatregel opleveren (RvT 22 februari 1980; JT 1982-1 en RvT 4 juni 1981; JT 1982-5). Stukken afkomstig van registeraccountants plegen indruk te maken; althans advocaten denken dat en zullen maar al te graag daarvan gebruik maken indien daardoor de positie van hun cliënt verstevigd zou kunnen worden. Een registeraccountant die weet of vermoedt dat zijn brief in een proces zou kunnen worden gebruikt, doet er daarom goed aan dit gebruik hetzij uitdrukkelijk te verbieden (bijv. door de zinsnede 'alleen voor persoonlijk gebruik; mag niet aan derden worden overgelegd'), hetzij zelf een advocaat te raadplegen omtrent de vraag of door overlegging van de brief aan de rechter zijn belang zou kunnen worden geschaad.

\section{De registeraccountant optredend in de accountantsfunctie}

Of een registeraccountant een misslag in zijn beroepsuitoefening heeft begaan bij het afgeven van een goedkeurende verklaring bij een verantwoording, wordt door de tuchtcolleges marginaal getoetst. De RvT gaat na of de accountant 'in redelijkheid de opvatting kon zijn toegedaan dat de jaarrekening aan de daaraan te stellen eisen voldeed' (RvT 26 januari 1979; JT 1980-1; zie hierna paragraaf 3.2), dan wel of de accountant 'in redelijkheid tot het afgeven van die verklaring had kunnen komen' (RvT 8 september 1976; De Acc. oktober 1978, no. 2, blz. 138 e.v. met noot van Groeneveld en commentaar van Frielink in De Acc. december 1979, blz. 319-321). Zie over deze marginale toetsing door de tuchtrechter mijn artikel in De Acc. maart 1979, blz. 469.

Een groot aantal kwesties op dit terrein zijn in de afgelopen vijf jaar aan het oordeel van de NIVRA-tuchtcolleges onderworpen. Hieronder zal ik nader ingaan op accountantscontrole en fraude (3.1) alsmede op de relatie tussen tuchtrechter en ondernemingskamer (3.2). 


\subsection{Accountantscontrole en interne fraude}

Een aantal malen werd een klacht ingediend omdat een goedkeurende verklaring was afgegeven terwijl achteraf bleek dat de cijfers een vertekend beeld gaven als gevolg van interne fraude. Er is hier een opvallend verschil van opvatting tussen het publiek enerzijds en beroepsgenoten anderzijds. Het publiek meent dat een goede accountantscontrole elke vorm van interne fraude aan het licht moet brengen. Beroepsgenoten staan op het standpunt dat ook bij een deugdelijke accountantscontrole niet alle vormen van fraude ontdekt behoeven te worden. De accountant dient zich bijvoorbeeld niet in te laten met kleine verschillen en onnauwkeurigheden in de administratie; kleine fraudes kunnen daardoor aan zijn aandacht ontsnappen. Ditzelfde geldt voor fraudes die plaatsvinden door middel van transacties die buiten de administratie om tot stand komen (vgl. Stibbe, De accountant en fraude MAB 1983, blz. 443-456).

Hoe oordeelt nu de RvT wanneer in een dergelijk geval een klacht wordt ingediend? In een uitspraak van de RvT van 8 juli 1977 (De Acc. april 1979, blz. 564) ging het, zoals Groeneveld het in zijn annotatie op de uitspraak beschrijft, om toepassing van geavanceerde controletechnieken onder omstandigheden waarin deze niet pasten. Er werd jaren achtereen een ruim gebruik gemaakt van steekproeven en gesteund op interne controle. De steekproeven werden niet voldoende gericht genomen waardoor de afdeling met de grootste voorraad buiten de steekproef bleef.

De RvT stelt voorop dat voor het tuchtrechtelijk oordeel alleen van belang is 'of de onder verantwoordelijkheid van de betrokken registeraccountant uitgevoerde controles zijn verricht in overeenstemming met de daarvoor geldende voorschriften en gebruiken, m.a.w. of betrokkenen in hun beroepsuitoefening terzake zijn tekort geschoten'.

De debiteurencontroles waren volgens de Rv'T op correcte wijze verricht. Ten aanzien van een gering aantal posten verspreid over een aantal jaren is achteraf gebleken dat bonnen of facturen afwezig of niet in orde waren. De RvT laat uitdrukkelijk in het midden of een opdracht tot controle van de jaarrekening impliceert het rapporteren omtrent eventuele lacunes in de interne organisatie. In het onderhavige geval was de accountant volgens de Raad op dit punt niet tekort geschoten.

Omvangrijke fraudes waren aan het licht gekomen bij de voorraadadministratie. Volgens de RvT hadden deze bij een volledige en deskundige controle ontdekt kunnen worden. De RvT is van oordeel dat de door de betrokkene stelselmatig toegepaste wijze van voorraadcontrole in ernstige mate uit vaktechnisch oogpunt tekortschoot en dat er mitsdien sprake was van een misslag in de uitoefening van het beroep als bedoeld in artikel 33 lid 1 van de Wet RA. De Raad legt de betrokkenen de maatregel van een schriftelijke berisping op. Een uitspraak die in hoger beroep wordt bevestigd (RvB 10 mei 1978; De Acc. april 1979, blz. 566).

Uit deze uitspraak blijkt dat indien fraude niet door accountantscontrole aan het licht is gekomen, voor de tuchtrechtelijke beoordeling de maatstaf wordt aangelegd die beroepsgenoten hanteren. De vraag of de verwachtingen die het publiek omtrent accountantscontrole koestert zijn beschaamd als fraudes bij een accountantscontrole niet worden ontdekt en of daardoor 
inbreuk is gemaakt op de eer van de stand der registeraccountants, komt bij de beoordeling niet ter sprake.

In een ander geval had de betrokken externe accountant uitdrukkelijk verklaard dat de interne controle bevredigend functioneerde. Dit nadat hij reeds beschikte over enige aanwijzingen voor het tegendeel. Toen later bleek dat de administrateur/directeur van de werkmaatschappij een omvangrijk bedrag had verduisterd, werd de ingediende klacht dan ook (gedeeltelijk) gegrond verklaard (RVT 10 maart 1981; JT 1983-1). In zijn noot onder de uitspraak stelt Groeneveld dat zijns inziens controle van de jaarrekening ook controle van de administratie omvat en dat de betrokken accountant gebreken daarin eigener beweging moet melden aan zijn opdrachtgever.

In het derde geval ging de opdracht aan de betrokken registeraccountant verder dan het enkel controleren van de jaarrekening. Tot zijn taak behoorde ook het begeleiden van de administratie. Hem werd verweten dat hij de enorme achterstanden die bij de administratie waren ontstaan en een aantal wezenlijke gebreken in de administratie slechts had gesignaleerd, maar had nagelaten de directie/opdrachtgever de ernst van de situatie onder ogen te brengen. Daardoor was voor de directie niet voldoende duidelijk geworden dat er ernstig gevaar bestond voor oninbaarheid van vorderingen en voor verduistering. De Rv'T legt terzake de maatregel van schriftelijke waarschuwing op (RvT 21 augustus 1981; JT 1983-2). De RvB bekrachtigt de beslissing van de Rv'T met de opmerkelijke correctie, dat het bezwaar tegen betrokkene niet als een inbreuk op de eer van de stand der registeraccountants, maar als een misslag in de uitoefening van zijn beroep moest worden aangemerkt (RvB 27 juli 1982; dT 1983-2).

\subsection{Tuchtrechter en Ondernemingskamer}

In de afgelopen periode van vijf jaar heeft de RvT zich een aantal malen (JT 1980-1, 4 en 6, 1981-11 en 1982-6) moeten uitspreken over gevallen waarin een accountant een goedkeurende verklaring had afgegeven bij een jaarrekening die later door de Ondernemingskamer (OK) in strijd met de wet werd bevonden. In het vorige overzicht (MAB 1979, blz. 46) heb ik reeds melding gemaakt van het in de Accountant van april 1978 gepubliceerde voornemen van het NIVRA-bestuur om wanneer zich zoiets voordoet van haar bevoegdheid ex artikel 40 Wet RA gebruik te maken en de RvT te verzoeken een onderzoek in te stellen. Dit voornemen is inmiddels enigszins afgezwakt in die zin, dat geen verzoek zal worden gedaan als de oK de jaarrekening ondanks strijdigheid met de wet niet heeft vernietigd omdat de geconstateerde gebreken van te weinig gewicht waren (zie De Accountant van februari 1980). Op het bestuursstandpunt is in de vakpers met instemming, maar ook kritisch gereageerd (zie o.m. De Jong, De Accountant april 1981, blz. 475/476; Beckman, De Accountant september 1981, blz. 20/21; Wessel, in de bundel Van Titel 6 naar Titel 8, NIVRA-Geschriften no. 24, Deventer 1981, blz. 68 en Maeijer in de bundel De jaarrekening en de Vierde EG-Richtlijn, Deventer 1981, blz. 24/25). Tot nog toe hoefde het NIVRAbestuur slechts tweemaal in actie te komen om een door de OK in strijd 
met de wet verklaarde jaarrekening die van een goedkeurende verklaring was voorzien aan de RvT ter onderzoek voor te leggen (JT 1980-6 en 19826). In twee andere gevallen had de eiser in de jaarrekeningprocedure de zaak bij de RVT aanhangig gemaakt (JT 1980-1 en JT 1981-11).

De RvT gaat er van uit dat de OK oordeelt over het gedrag van ondernemingen en de Raad over het gedrag van accountants. De bevoegdheden van beide colleges sluiten elkaar niet uit (JT 1980-4; zie omtrent samenloop van uitspraken van de RvT en die van de OK: Sluyter, De Accountant juni 1977, blz. 609-612). De oK beslist of de jaarrekening in strijd is met de wet; de RvT gaat na of de accountant 'in aanmerking genomen de ten tijde van zijn verklaring geldende, in het maatschappelijk verkeer als aanvaardbaar beschouwde, opvattingen en de voor hem geldende gedrags- en beroepsregels in redelijkheid de opvatting kon zijn toegedaan dat de jaarrekening aan de daaraan te stellen eisen voldeed' (GBR artikel 13 lid 1 en RvT 26 januari 1979, JT 1980-1).

Tot de eisen waaraan de jaarrekening moet voldoen behoren in ieder geval de eisen die de wet stelt. Aanvankelijk waren deze eisen vermeld in de Wet op de Jaarrekening van Ondernemingen (wJO), sedert 1976 in het tweede boek van het Burgerlijk Wetboek (Boek 2 BW); aanvankelijk in titel 6, sedert 1 januari 1984 in titel 8. De RvT toetst zelfstandig de jaarrekening aan de wettelijke eisen en vraagt zich daarbij af, niet of de jaarrekening aan de wettelijke eisen voldoet, maar of de accountant mocht aannemen dat de jaarrekening overeenkomstig de wet was opgesteld. Dit leidt er toe dat op punten waar de OK heeft beslist dat de jaarrekening in strijd was met de wet, de RvT toch tot het oordeel kan komen dat de controlerend accountant had mogen aannemen dat zulks niet het geval was (zie het overzicht dat Groeneveld heeft opgesteld in zijn annotatie bij RvT 26 januari 1979; JT 1980-1, blz. 10).

Ik acht de benadering van de RvT juist en de daaruit voortvloeiende consequentie aanvaardbaar. Er zijn nu eenmaal punten waarop men bij toepassing van de wet in redelijkheid van mening kan verschillen. Ook al zou de controlerend accountant van mening zijn dat toepassing van de wet een bepaald gevolg heeft voor de inrichting van de jaarrekening, hij mag zijn goedkeurende verklaring niet onthouden aan een jaarrekening waarin met dit gevolg geen rekening is gehouden als de onderneming van mening is - en in redelijkheid van mening kon zijn - dat met dit gevolg geen rekening gehouden behoeft te worden.

Anders ligt de zaak echter als de Ondernemingskamer omtrent het betreffende punt een ondubbelzinnige uitspraak heeft gedaan die in kracht van gewijsde is gegaan. De accountant heeft zich bij een dergelijke uitspraak neer te leggen. Niet omdat een andere opvatting niet meer redelijk zou zijn, maar omdat volgens de regels van ons rechtsstelsel alleen de overheidsrechter omtrent de betekenis van wettelijke begrippen bindende uitspraken doet. Aanvechtbaar vind ik dan ook de overweging van de RvT dat de accountant de door de rechter gegeven uitleg van de wettelijke bepaling 'als een zwaarwegend gegeven heeft te aanvaarden zonder nochtans de verdere ontwikkeling van de opvattingen omtrent hetgeen in het maatschappelijk verkeer aanvaardbaar wordt geacht, uit het oog te verliezen' (JT 1980-1, blz. 
2). Een accountant heeft zich te houden aan regels van Nederlands recht. Het is niet zijn taak, maar die van de wetgever en de rechter om te beoordelen of deze regels zich verdragen met 'de verdere ontwikkelingen van de opvattingen omtrent hetgeen in het maatschappelijk verkeer aanvaardbaar wordt geacht' (zie over deze kwestie het uitstekende artikel van Leonard Hoffman QC en Mary H. Arden, Legal opinion on 'true and fair', Accountancy, november 1983, blz. 154-156).

Als de RvT vaststelt dat de jaarrekening in strijd is met de wet en dat geen goedkeurende verklaring had mogen worden afgegeven, dan is er sprake van een misslag in de uitoefening van het beroep. Wel is het mogelijk dat de RvT tot de conclusie komt dat deze misslag niet van zodanige betekenis is dat er aanleiding is voor het opleggen van een maatregel (RvT 10 april 1979; JT 1980-4). Vergelijk in dit verband ook de uitspraken JT 1980-6 en JT 1981-11. Naar het oordeel van de RvT was de jaarrekening strijdig met de wet en had de controlerend accountant niet mogen volstaan met afgifte van een verklaring van oordeelonthouding; ook hier zag de RvT geen aanleiding voor het opleggen van een maatregel.

\section{Slotopmerking}

In de vakliteratuur van de afgelopen jaren worden pleidooien gevoerd om in het tuchtprocesrecht een instantie in te stellen die als aanklager fungeert (zie bijvoorbeeld het in 1981 verschenen proefschrift van De Doelder, Terrein en beginselen van tuchtrecht). Een dergelijke instantie zou, stelselmatiger dan het NIVRA-bestuur nu doet, kunnen onderzoeken of de leden van het NIVRA bij het afgeven van verklaringen rekening hebben gehouden met de normen die op het gebied van de jaarverslaggeving gelden. Het ambtshalve inleiden van een tuchtrechtelijk onderzoek zou dan kunnen geschieden als een registeraccountant blijkt herhaaldelijk misslagen te begaan bij de uitoefening van zijn controlefunctie; daarmee hoeft dan niet te worden gewacht tot deze misslagen - bijvoorbeeld als gevolg van publiciteit - de eer van de stand in gevaar brengen vgl. in dit verband ook de aanbeveling op blz. 88 van het rapport Neutraal maar niet passief, NIVRA 1980. Bovendien zou het ingangzetten en voortzetten van een tuchtprocedure dan niet langer afhankelijk zijn van het initiatief en het doorzettingsvermogen van individuele klagers. Ook om uitvoering te geven aan de in artikel 11 van het ontwerp Achtste Europese Richtlijn aan de tuchtcolleges opgedragen toezichthoudende taken zou instelling van een vervolgende instantie het overwegen waard zijn. 